\title{
Article \\ A Resonant Pressure Microsensor with a Wide Pressure Measurement Range
}

\author{
Chao Xiang ${ }^{1,2}$, Yulan Lu ${ }^{1,2}$, Chao Cheng ${ }^{1,2}$, Junbo Wang ${ }^{1,2, *}$, Deyong Chen ${ }^{1,2, *}$ and Jian Chen ${ }^{1,2}(\mathbb{D}$ \\ 1 Aerospace Information Research Institute, Chinese Academy of Sciences, Beijing 100190, China; \\ xiangchao115@mails.ucas.ac.cn (C.X.); luyulan15@mails.ucas.ac.cn (Y.L.); \\ chengchao18@mails.ucas.ac.cn (C.C.); chenjian@mail.ie.ac.cn (J.C.) \\ 2 School of Electronic, Electrical and Communication Engineering, University of Chinese Academy of Sciences, \\ Beijing 100049, China \\ * Correspondence: jbwang@mail.ie.ac.cn (J.W.); dychen@mail.ie.ac.cn (D.C.); Tel.: +86-010-588-87191 (J.W.); \\ $+86-010-588-87182$ (D.C.)
}

check for updates

Citation: Xiang, C.; Lu, Y.; Cheng, C.; Wang, J.; Chen, D.; Chen, J. A

Resonant Pressure Microsensor with a Wide Pressure Measurement Range. Micromachines 2021, 12, 382. https:// doi.org/10.3390/mi12040382

Academic Editors: Libo Zhao and Ha Duong Ngo

Received: 9 February 2021

Accepted: 27 March 2021

Published: 1 April 2021

Publisher's Note: MDPI stays neutral with regard to jurisdictional claims in published maps and institutional affiliations.

Copyright: (c) 2021 by the authors. Licensee MDPI, Basel, Switzerland. This article is an open access article distributed under the terms and conditions of the Creative Commons Attribution (CC BY) license (https:// creativecommons.org/licenses/by/ $4.0 /)$.
Abstract: This paper presents a resonant pressure microsensor with a wide range of pressure measurements. The developed microsensor is mainly composed of a silicon-on-insulator (SOI) wafer to form pressure-sensing elements, and a silicon-on-glass (SOG) cap to form vacuum encapsulation. To realize a wide range of pressure measurements, silicon islands were deployed on the device layer of the SOI wafer to enhance equivalent stiffness and structural stability of the pressure-sensitive diaphragm. Moreover, a cylindrical vacuum cavity was deployed on the SOG cap with the purpose to decrease the stresses generated during the silicon-to-glass contact during pressure measurements. The fabrication processes mainly contained photolithography, deep reactive ion etching (DRIE), chemical mechanical planarization (CMP) and anodic bonding. According to the characterization experiments, the quality factors of the resonators were higher than 15,000 with pressure sensitivities of $0.51 \mathrm{~Hz} / \mathrm{kPa}$ (resonator I), $-1.75 \mathrm{~Hz} / \mathrm{kPa}$ (resonator II) and temperature coefficients of frequency of $1.92 \mathrm{~Hz} /{ }^{\circ} \mathrm{C}$ (resonator I), $1.98 \mathrm{~Hz} /{ }^{\circ} \mathrm{C}$ (resonator II). Following temperature compensation, the fitting error of the microsensor was within the range of $0.006 \% \mathrm{FS}$ and the measurement accuracy was as high as $0.017 \% \mathrm{FS}$ in the pressure range of $200 \sim 7000 \mathrm{kPa}$ and the temperature range of $-40^{\circ} \mathrm{C}$ to $80^{\circ} \mathrm{C}$.

Keywords: resonant pressure microsensor; wide pressure measurement range; silicon islands; cylindrical vacuum cavity; quality factor

\section{Introduction}

In the fields of industrial control, aerospace and deep-sea exploration, pressure sensors with a wide measurement range (over several atmospheric pressure) are widely used [1] These pressure sensors mainly function with several typical working principles, such as piezoresistive sensing [2-4], piezoelectric sensing [5,6], capacitive sensing [7,8], fiber optical sensing $[9,10]$ and resonant sensing [11-17]. Piezoresistive pressure sensors are widely used in many areas because of significant advantages, including high sensitivities, fast dynamic responses and easy miniaturizations. Nevertheless, piezoresistive pressure sensors are sensitive to temperature variations and thus suffer from limited resolutions [18]. Compared with piezoresistive pressure sensors, although piezoelectric pressure sensors are not sensitive to temperature variations, they cannot measure pressures without variations as a function of time [19]. As another type of pressure sensor which is not sensitive to temperature variations, a capacitive pressure sensor requires complex detection circuits [20]. Fiber optical pressure sensors are immune to electromagnetic interferences, and thus they can work in harsh environments. However, the fabrication of fiber optical pressure sensors is quite complex [21]. Compared to other kinds of pressure sensors, resonant pressure 
sensors feature high accuracies, high resolutions, quasi-digital outputs and high long-term stabilities [22-26].

J.C. Greenwood presented a silicon resonant sensor for measuring a wide pressure range up to $48.265 \mathrm{MPa}$ in 1994 [27]. The resolution of this sensor was better than $100 \mathrm{ppm}$ with the total errors better than $0.02 \% \mathrm{FS}$ from $-20{ }^{\circ} \mathrm{C}$ to $70{ }^{\circ} \mathrm{C}$ [28]. In 2009, P.K. Kinnell presented a Micro-Electro-Mechanical System (MEMS) resonant pressure sensor employing a flexible fabrication route, including direct silicon fusion bonding and deep reactive ion etching (DRIE) [29]. Theoretically, the sensor can measure $700 \mathrm{bar}(70,000 \mathrm{kPa})$ in a hermetic package. Experimental results showed that the total errors of the sensor were less than $40 \mathrm{ppm}$ over a temperature range of $-54{ }^{\circ} \mathrm{C}$ to $125^{\circ} \mathrm{C}$ and a pressure range of 0 to $200 \mathrm{kPa}$. Yiwen Jiang presented a micromachined resonant pressure sensor based on a fully symmetrical structure in 2012 [30]. Experimental results showed that the sensor had a pressure sensitivity of about $22.6 \mathrm{~Hz} / \mathrm{kPa}$, within the pressure range up to $550 \mathrm{kPa}$. In addition, $\mathrm{H}$. Mitsuya introduced a resonant pressure sensor based on squeeze-film damping in a $2 \mu \mathrm{m}$ driving/sensing gap of a silicon ring-shaped resonator in 2014 [31]. The reported data showed that the sensitivity was $1.8 \mathrm{~Hz} / \mathrm{kPa}$ under a measurement range of $10 \mathrm{kPa}$ to $1 \mathrm{MPa}$. Furthermore, our previous studies focused on several types of resonant pressure sensors with pressure measurement ranges over $500 \mathrm{kPa}$, such as $\mathrm{Lu}$ (2019) [32], Yan (2019) [33] and Xiang (2020) [34], with s maximal value of $2 \mathrm{MPa}$.

When the range of pressure measurements is expanded from $0 \sim 2 \mathrm{MPa}$ to $0 \sim 7 \mathrm{MPa}$, the maximum deformation of the pressure-sensitive diaphragm is over several micrometers. Therefore, the microsensor works in a nonlinear state and the accuracy of the microsensor decreases. If the maximum stress on the pressure-sensitive diaphragm is higher than the breaking strength of silicon, the microsensor can be damaged permanently. Hence, the key points of expanding the pressure measurement range of the microsensor are reasonable design of the microsensor's structures, regulating pressure sensitivities and increasing structural strength of the microsensor.

In order to address this issue, this study presented a resonant pressure microsensor based on a specific design to downregulate the pressure sensitivities, improve the structural strength of the microsensor and eventually further enlarge the pressure measurement range. The specific design optimized the shape of the vacuum cavity and the parameter of the resonant beams. By employing this specific design, the pressure measurement errors of this microsensor were less than $0.02 \%$ FS from $80{ }^{\circ} \mathrm{C}$ to $-40{ }^{\circ} \mathrm{C}$ and over a pressure range of 200 to $7000 \mathrm{kPa}$. Moreover, compared with the resonant pressure sensors which were reported before, the package of this microsensor was easy to conduct. This paper (1) introduced the design of the microsensor, (2) estimated maximum stresses under high pressures and obtained frequency responses of the resonant microsensor based on theoretical calculations and numerical simulations, (3) realized the fabrication of the microsensor based on MEMS, (4) validated the microsensor by employing several experiments including open-loop and closed-loop tests.

\section{Theoretical Analysis}

\subsection{Working Principle}

As shown in Figure 1a, the proposed resonant pressure sensor mainly consists of a silicon-on-insulator (SOI) layer as sensing elements and a silicon-on-glass (SOG) cap (including a glass layer and a silicon layer) with a cavity for vacuum packaging. The sensing elements include a pressure-sensitive diaphragm and a pair of resonators. To keep the two resonators working linearly in a wide pressure measurement range and increase the structural strength of the microsensor to bear larger pressures, the whole handle layer functions as a pressure-sensitive diaphragm for the purpose of increasing the thickness of the pressure-sensitive diaphragm. Besides, the device layer is used to form a pair of H-shaped doubly clamped resonators (including "resonator I" located in the central areas of the diaphragm and "resonator II" located in the edge areas of the diaphragm, respectively). Additionally, electronic connections are formed by eight through silicon vias 
(TSVs). The SOG cap with a cylindrical cavity could strongly reduce the stress between the SOI layer and the SOG layer during high-pressure measurements. Meanwhile, four silicon islands are designed in the device layer of the SOI wafer. The silicon islands can be regarded as a part of the pressure-sensitive diaphragm, which can increase the thickness of the pressure-sensitive diaphragm further (as shown in Figure 1b).

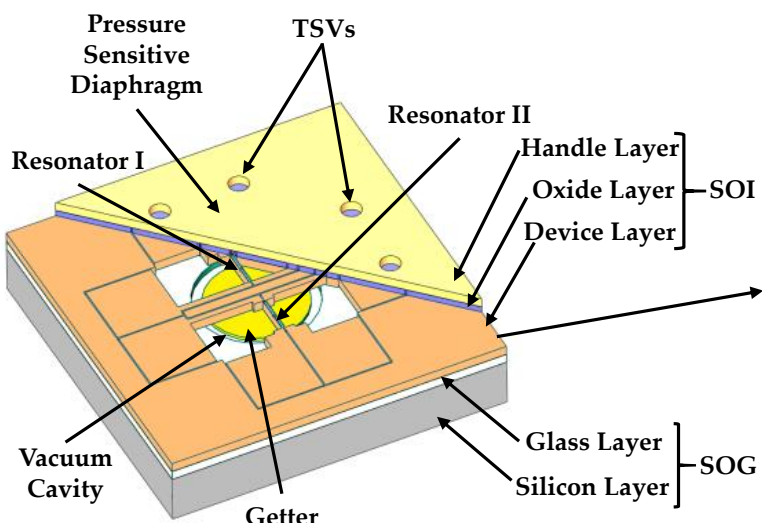

(a)

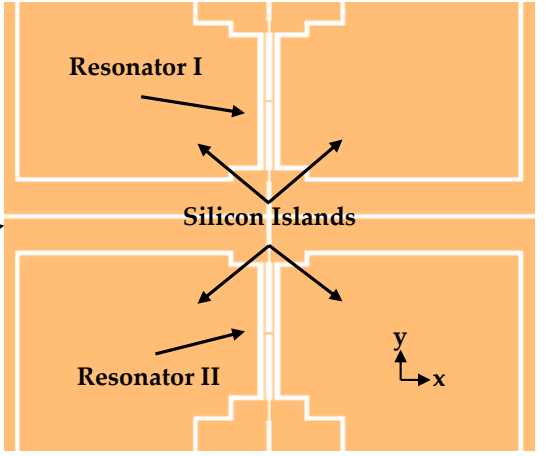

(b)

Figure 1. (a) Schematic of the resonant pressure sensor, including a silicon-on-insulator (SOI) layer and a silicon-on-glass (SOG) cap. In the SOI wafer, there is a pressure-sensitive diaphragm, eight TSVs in the handle layer and two H-shaped doubly clamped resonators in the device layer. In the device layer of the SOI, four silicon islands are hidden to show the vacuum cavity. The SOG cap with a cavity, evaporated with the getter material, was used to form vacuum packaging for the resonators and reduce the temperature sensitivity of the resonant pressure sensor; (b) detailed structure of sensing elements.

Pressure under measurement causes the deformation of the pressure-sensitive diaphragm, changing the axial stress of the resonators (see Figure 2a). Hence, the intrinsic resonant frequencies of the two resonators shift. By measuring these two resonant frequencies, the pressure can be calculated. Meanwhile, differential outputs of the two resonators' frequencies can decrease the influence caused by temperature variations and increase the pressure sensitivities of the pressure measurements.

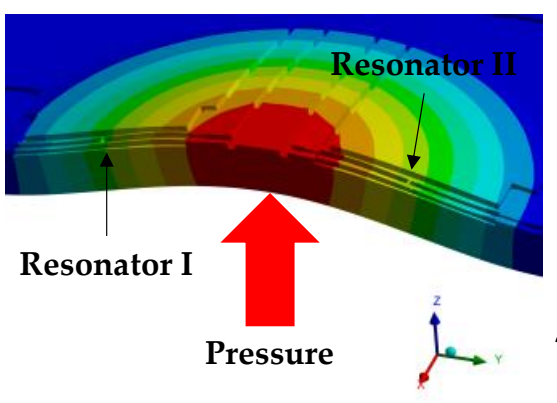

(a)

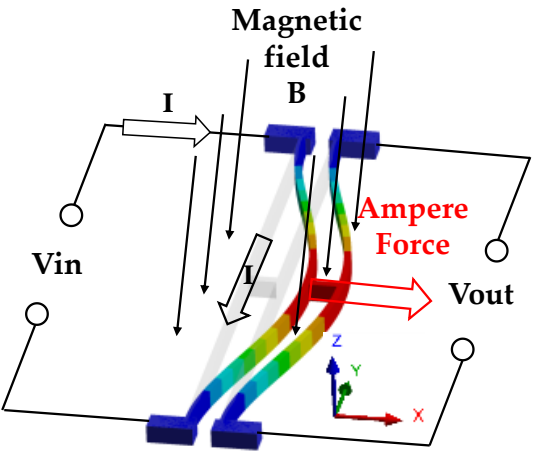

(b)

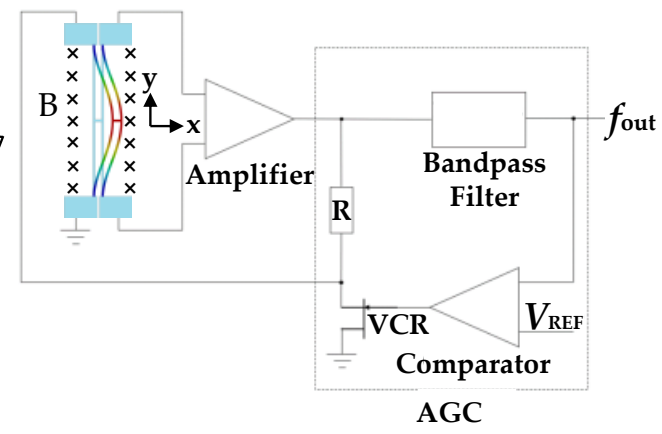

(c)

Figure 2. (a) The stress distribution on sensing elements under pressure; (b) the working principle of the resonator; (c) the working principle of the presented microsensor.

According to Figure 1, the resonators of the presented microsensor are two " $\mathrm{H}$ " beams. These two resonators vibrate laterally at the first-order modal (see Figure 2b).

The proposed microsensor was based on electro-magnetic excitation/electro-magnetic detection. Additionally, the detailed detection principle was as follows. Carrying an AC 
current, the resonator vibrated due to Ampère's force, in a static magnetic field which is perpendicular to the pressure-sensitive diaphragm. The resulting vibration of the resonator produced a magnetic induction voltage, which was further processed with the help of amplifier and bandpass filters, for the extraction of the frequency signals (see Figure 2c). Then, the comparison between the magnitude of the output frequency signal and a constant voltage $\left(\mathrm{V}_{\mathrm{REF}}\right)$ was used to control the resistance of a voltage-controlled resistor (VCR). Therefore, the driving signal of the resonator can be controlled to keep outputting a signal with constant magnitude. This principle of the circuit is called automatic gain control (AGC). These two output frequencies of the microsensor are functions of pressure and temperature. After calibration, employing a polynomial fitting method based on differential outputs and a temperature sensor, the microsensor's temperature compensation can be achieved in a wide pressure measurement range [34].

\subsection{Optimal Design and Finite Element Analysis (FEA) Simulations}

A wide pressure measurement range means the microsensor should work in a highpressure environment. The microsensor presented in this paper was designed to work from $200 \mathrm{kPa}$ to $7000 \mathrm{kPa}$. Therefore, the design must ensure that the microsensor can work stably under $7000 \mathrm{kPa}$. In order to analyze the status of the microsensor working at $7000 \mathrm{kPa}$, theoretic analysis was employed.

According to structural mechanics [35], the maximum stresses of the microsensor at the interface between silicon and glass should be

$$
\left(\sigma_{r r}\right)_{\max }=\alpha \cdot \frac{A}{h^{2}} P
$$

where $\alpha$ is the parameter of the pressure-sensitive diaphragm shape as shown in Table $1, P$ is the outside pressure, $A$ is area of the pressure-sensitive diaphragm, and $h$ is the thickness of the pressure-sensitive diaphragm.

Table 1. Shape parameters of pressure-sensitive diaphragm [35].

\begin{tabular}{cc}
\hline Items & $\alpha$ \\
\hline Square & 0.31 \\
Circle & 0.24 \\
\hline
\end{tabular}

Equation (1) shows that the maximum stress on the microsensor mainly depended on the area and the shape of the pressure-sensitive diaphragm. Additionally, the stress on a circular pressure-sensitive diaphragm was smaller than the square counterpart of the same area.

To verify the design of the microsensor, FEA simulations based on ANSYS were employed to evaluate the maximum stress on the microsensors with two different pressuresensitive diaphragms. The diameter of the circular pressure-sensitive diaphragm was equal to the side length of the square pressure-sensitive diaphragm.

Figure $3 a, b$ proves that the maximum stress on the circular pressure-sensitive diaphragm was smaller than the stress on the square counterpart under $7000 \mathrm{kPa}$.

For the sake of choosing a suitable size of vacuum cavity to make the microsensor work well at $7 \mathrm{MPa}$, several chips with different vacuum cavity sizes were fabricated to conduct pressure loading experiments. The parameters of these chips are listed in Table 2. The shape of type A and B was a square, while the shape of type C and D was a circle. 


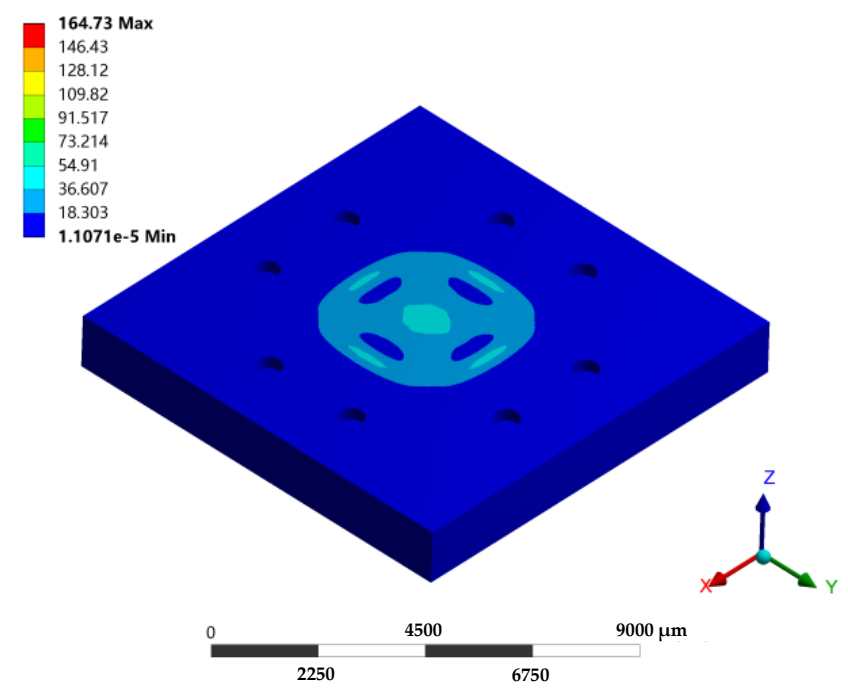

(a)

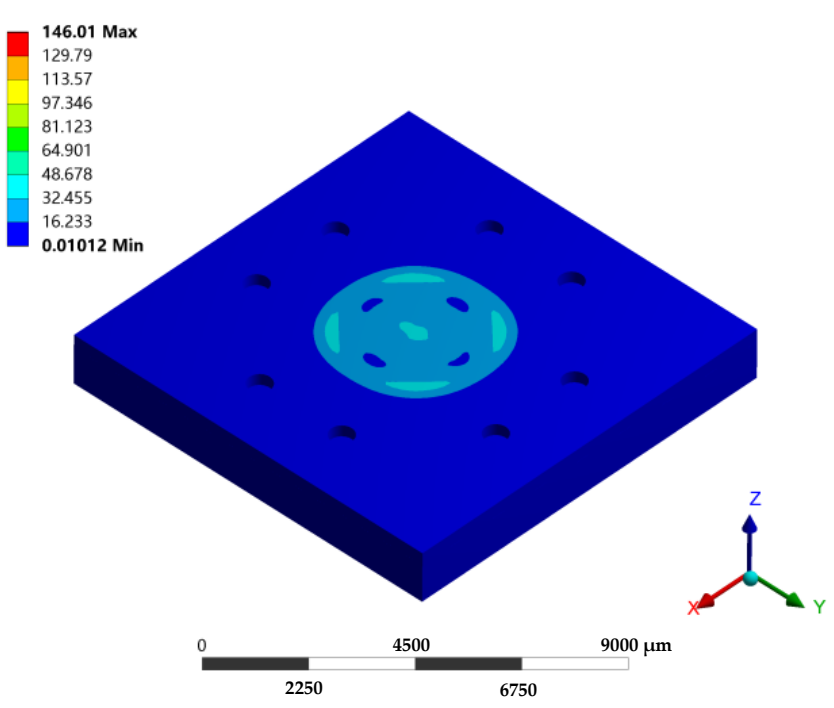

(b)

Figure 3. (a) Structural simulations under $7000 \mathrm{kPa}$ : (a) the microsensor with square pressure-sensitive diaphragm (side length of $4.4 \mathrm{~mm}$ ); (b) the microsensor with circular pressure-sensitive diaphragm (diameter of $4.4 \mathrm{~mm}$ ).

Table 2. Parameters of chips with different vacuum cavity sizes.

\begin{tabular}{cccc}
\hline Type & Length $/ \mathbf{m m}$ & Width $/ \mathbf{m m}$ & Diameter $/ \mathbf{m m}$ \\
\hline A & 5 & 5 & - \\
B & 3.6 & 3.6 & - \\
C & - & - & 5 \\
D & - & - & 3.6 \\
\hline
\end{tabular}

Table 3 shows the experimental results with different sizes under several pressure points. When the diameter of the vacuum cavity was $3.6 \mathrm{~mm}$, the maximum safe loading pressure can reach $40 \mathrm{MPa}$, which suggests the strength of the microsensor can meet the requirement. Therefore, the diameter of the presented microsensor's vacuum cavity was set as $3.56 \mathrm{~mm}$.

Table 3. Experimental results of pressure loading on chips with different sizes.

\begin{tabular}{cccccc}
\hline Type & $\mathbf{1 1} \mathbf{M P a}$ & $\mathbf{2 0 ~ M P a}$ & $35 \mathrm{MPa}$ & $\mathbf{4 0 ~ M P a}$ & $60 \mathrm{MPa}$ \\
\hline A & Broken & - & - & - & - \\
B & OK & OK & Broken & - & - \\
C & OK & Broken & - & - & - \\
D & OK & OK & OK & OK & Broken \\
\hline
\end{tabular}
Table 4.

The dimensional information of the microsensor model in FEA simulations is listed in

Table 4. Dimensional information of the microsensor model in FEA simulations.

\begin{tabular}{|c|c|c|c|c|c|}
\hline Part & Length/ $\mu \mathrm{m}$ & Width $/ \mu \mathrm{m}$ & Thickness/ $\mu \mathrm{m}$ & Depth/ $\mu \mathrm{m}$ & Diameter/ $\mu \mathrm{m}$ \\
\hline Resonant Beam & 1200 & 16.5 & 40 & - & - \\
\hline Device Layer of SOI & 10,200 & 10,200 & 40 & - & - \\
\hline Handle Layer of SOI & 10,200 & 10,200 & 300 & - & - \\
\hline Oxide Layer of SOI & 10,200 & 10,200 & 2 & - & - \\
\hline Vacuum Cavity & - & - & - & 10 & 3560 \\
\hline Glass Layer of SOG & 10,200 & 10,200 & 120 & - & - \\
\hline Silicon Layer of SOG & 10,200 & 10,200 & 1500 & - & - \\
\hline
\end{tabular}


Several simulations were also conducted to calculate the intrinsic frequency shifts in response to pressure and temperature variations, relying on multi-models of steady-state thermal, static structural, and modal. In simulations, tetrahedral elements were used to mesh geometrical structures of the microsensor with 2,265,845 elements.

The materials used in simulations are listed in Table 5. In addition, a meshing size of $100 \mu \mathrm{m}$ was used to mesh the entire body. Finally, the resonant frequencies were calculated as the temperature dropped from bonding temperature $\left(350^{\circ} \mathrm{C}\right)$ to an ambient working temperature range $\left(-40 \sim 80^{\circ} \mathrm{C}\right)$.

Table 5. Material properties in FEA simulation.

\begin{tabular}{ccc}
\hline Item & Silicon & BF33 \\
\hline Young's modulus $(\mathrm{GPa})$ & 165 & 64 \\
Density $\left(\mathrm{g} / \mathrm{cm}^{3}\right)$ & 2.33 & 2.23 \\
Poisson's ratio & 0.28 & 0.2 \\
\hline
\end{tabular}

Resonator I was designed to measure the pressure change. Meanwhile, resonator II was designed to realize temperature compensation. In the static structure, pressures from $200 \mathrm{kPa}$ to $7000 \mathrm{kPa}$ were used as the loads. The generated stress distributions within the structures were then used as the loads for the modal analysis, and the outputs of the simulations were the intrinsic frequency shifts of the resonators in response to the pressure applied.

The initial conditions of temperature properties in simulations were set with a reference temperature of $350^{\circ} \mathrm{C}$, which is the anodic bonding temperature of the SOG cap and the SOI wafer. In fact, in order to facilitate the comparison with experimental results, a reference pressure of $100 \mathrm{kPa}$ was introduced into the static structure. In the steady-state thermal simulations, temperatures from -40 to $80{ }^{\circ} \mathrm{C}$ were used as the loads and the temperature distributions of the whole structure were transferred to the static structure. The calculated stresses within the structures were then used as the loads for the modal analysis, and the outputs of the simulations were the intrinsic frequencies of the resonators in response to temperature variances.

In addition, the intrinsic frequency shifts as a function of applied pressures and surrounding temperature variations are shown in Figure $4 \mathrm{a}, \mathrm{b}$. The pressure sensitivities of the two resonators were quantified as $0.56 \mathrm{~Hz} / \mathrm{kPa}$ (resonator I) and $-1.23 \mathrm{~Hz} / \mathrm{kPa}$ (resonator II) in the pressure range from $200 \mathrm{kPa}$ to $7000 \mathrm{kPa}$ under a reference temperature of $20^{\circ} \mathrm{C}$. In addition, the temperature sensitivities were quantified as $1.95 \mathrm{~Hz} /{ }^{\circ} \mathrm{C}$ (resonator I) and $1.83 \mathrm{~Hz} /{ }^{\circ} \mathrm{C}$ (resonator II) at $0{ }^{\circ} \mathrm{C}$ under a reference pressure of $100 \mathrm{kPa}$. 


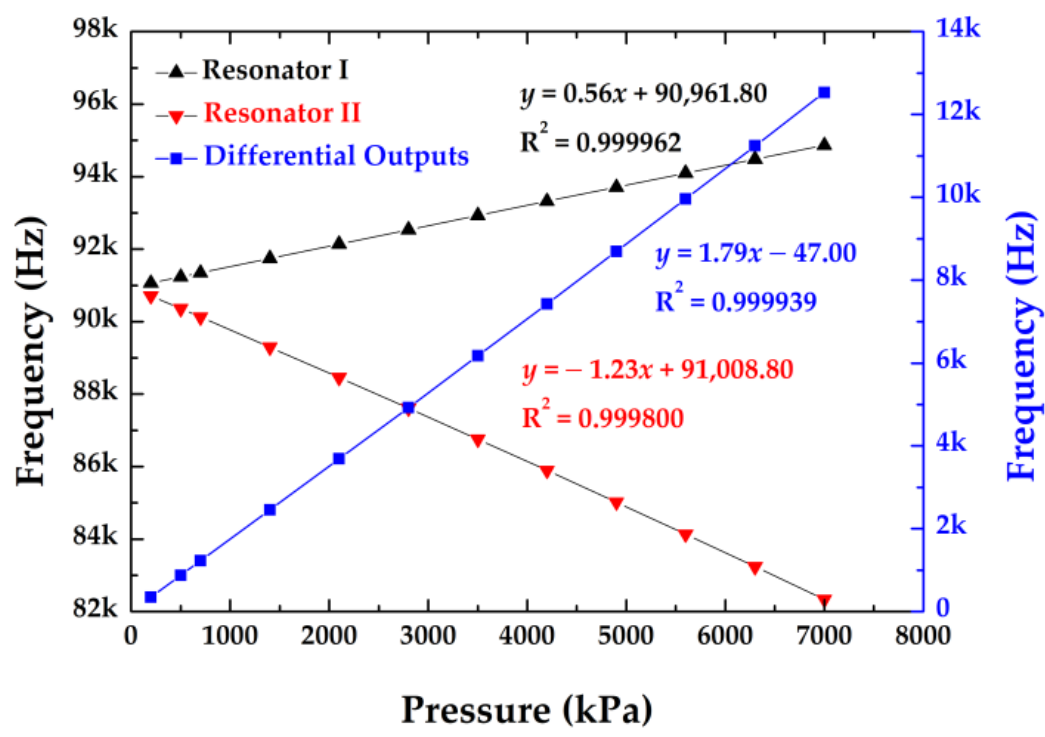

(a)

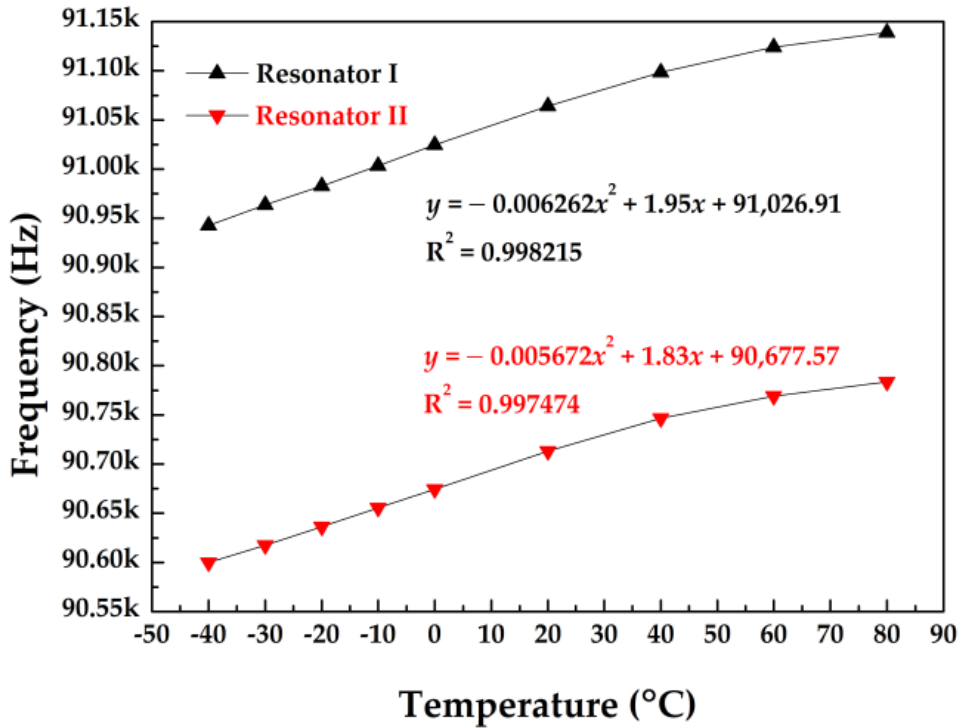

(b)

Figure 4. (a) The pressure-frequency curve of the developed sensor at $20^{\circ} \mathrm{C}$; (b) the temperaturefrequency curve of the developed sensor under $100 \mathrm{kPa}$.

\section{Fabrication}

Simple SOI-MEMS processing technologies were used to fabricate the proposed resonant beams and through silicon vias (see Figure 5). In the fabrication process, a 4 " SOI wafer (device layer: $40 \mu \mathrm{m},<100>$ oriented, p-type, doping concentration of $7.7 \times 10^{19}$; oxide layer: $2 \mu \mathrm{m}$; and handle layer: $300 \mu \mathrm{m},<100>$ oriented, p-type, doping concentration of $6.6 \times 10^{14} \sim 13 \times 10^{14}$ ), a $4^{\prime \prime}$ BF33 glass wafer with a thickness of $500 \mu \mathrm{m}$ and a 4 " silicon wafer with a thickness of $1500 \mu \mathrm{m}$ were employed in device fabrication. The main fabrication steps included deep reactive ion etching, hydrofluoric (HF) releasing and anodic bonding. 
(a)

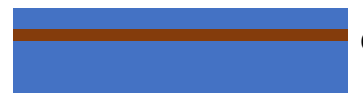

(b)

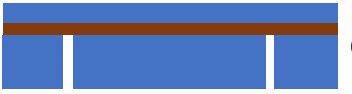

(f)

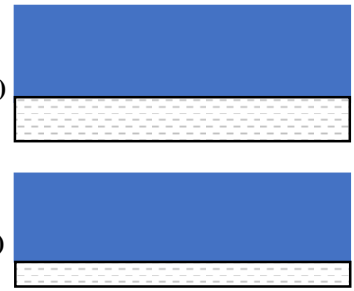

(c)

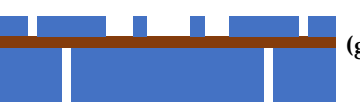

(d)

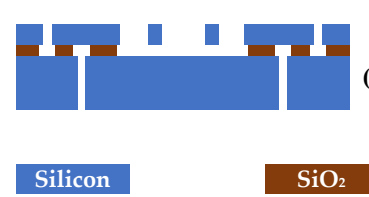

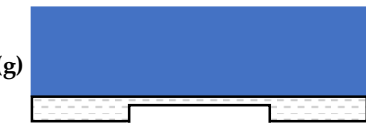

(h)

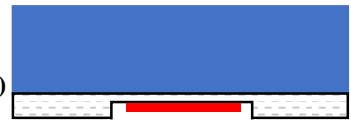

Glass - (i)

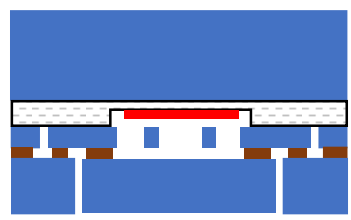

(j)

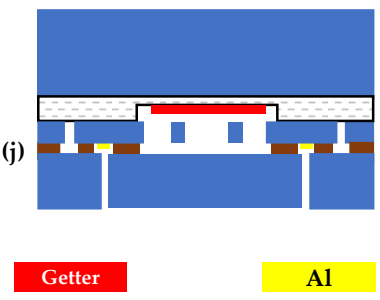

Figure 5. The fabrication processes of the sensor based on SOI-MEMS technologies. (a) Cleaning the SOI wafer; (b) conducting lithography to make through silicon vias on the handle layer; (c) conducting the second deep reactive ion etching (DRIE) on the device layer to form pressure-sensitive structures; (d) releasing resonant beams by HF; (e) conducting anodic bonding between a silicon wafer and a BF33 glass wafer; (f) thinning the glass layer of the SOG wafer by chemical mechanical planarization (CMP); (g) dry etching the glass wafer; (h) evaporating getters on the cavity; (i) conducting anodic bonding between the SOI and the SOG wafers; $(\mathbf{j})$ evaporating aluminum electrodes for wire connections.

First, the SOI wafer was immersed in deionized water and dried with pure $\mathrm{N}_{2}$ gas after being cleaned by piranha etchant to remove organic residues and boiled deionized water to remove soluble ions (see Figure 5a). Second, $100 \mathrm{~nm} \mathrm{Cr}$ was sputtered on the device layer to protect the device layer during the etching step on the handle layer, and then, using patterned photoresist as a mask, the handle layer of the SOI wafer was etched through to the oxide layer, forming the through silicon vias (see Figure $5 b$ ). Third, employing patterned photoresist and the $\mathrm{Cr}$ film as a compound mask, the device layer of the SOI wafer was etched through to the oxide layer, forming the sensitive structures (see Figure 5c). Fourth, lifting off the photoresist and $\mathrm{Cr}$ on the wafer was conducted based on the same process of the first step to clean the wafer. Additionally, the resonant beams were released by dry etching, employing HF solution and isopropanol in an alternate process (see Figure 5d).

The SOG wafer was made by conducting anodic bonding between a silicon wafer and a BF33 glass wafer (see Figure 5e). Additionally, the glass layer of the SOG wafer was thinned by chemical mechanical planarization (CMP) (see Figure 5f). The cavities for containing the vibration of the resonators in the BF33 glass wafer were drilled by HF dry etching (see Figure $5 \mathrm{~g}$ ). Then, a Ti/ $\mathrm{Au}$ thin film was evaporated on the cavity as the getter material for gas absorption during the next anodic bonding process (see Figure $5 \mathrm{~h}$ ).

After finishing the fabrications of the SOI and the SOG wafers, anodic bonding was utilized to form a vacuum encapsulation for resonators where the voltage, vacuum level, tool pressure and temperature of anodic bonding were set at $400 \mathrm{~V}, 0.1 \mathrm{~Pa}, 100 \mathrm{kPa}$ and $350{ }^{\circ} \mathrm{C}$, respectively (see Figure $5 \mathrm{i}$ ). The vacuum level of the vacuum cavity of the microsensor after anodic bonding was about 10 20 Pa. Then, aluminum films were evaporated on the TSVs of the bonding wafer to form electrical connections by a hard mask which was a glass wafer with through glass vias (TGVs) fabricated by laser processing (see Figure 5j). For isolating the silicon side walls, the diameter of TGVs $(0.4 \mathrm{~mm})$ on the glass wafer were smaller than TSVs $(0.6 \mathrm{~mm})$ on the handle layer of the SOI wafer. Ohmic contacts were formed by annealing the wafer in a $450{ }^{\circ} \mathrm{C}$ furnace for $30 \mathrm{~min}$. 
Figure 6 shows the fabrication results of the microsensor, containing the top view of the resonator (see Figure 6a), the scanning electron microscopy (SEM) cross-section image of the resonator (see Figure $6 \mathrm{~b}$ ), the top view of the microsensors after dicing (see Figure $6 \mathrm{c}$ ) and the side view of the microsensor (see Figure $6 \mathrm{~d}$ ).

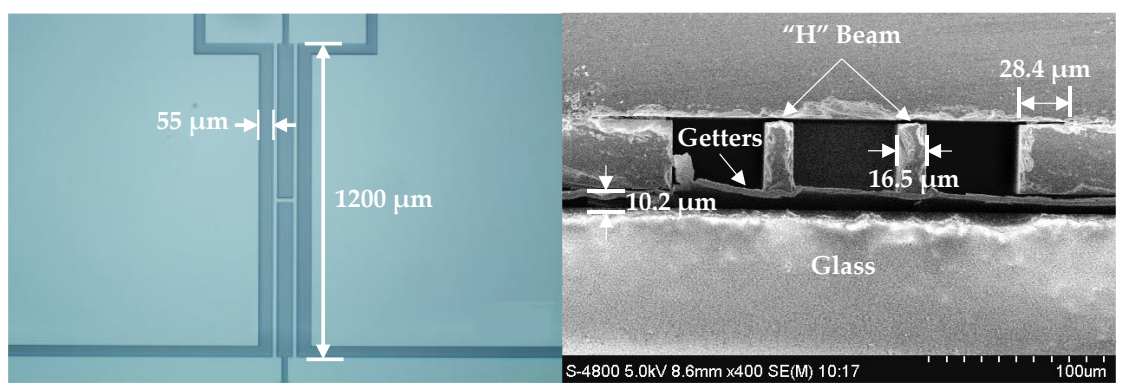

(a)

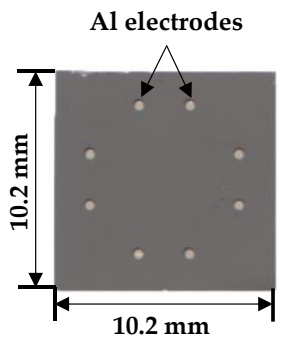

(c) (b)

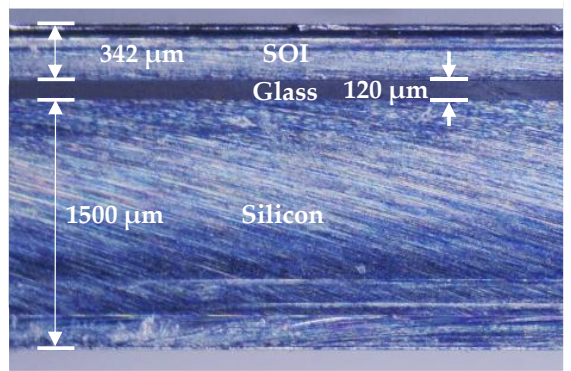

(d)

Figure 6. The fabrication results: (a) top view of the " $\mathrm{H}$ " resonant beam; (b) an SEM cross-section image of the microsensor; (c) top view of the microsensor and (d) side view of the microsensor.

As shown in Figure 7a, the fabricated microsensor was fixed to the Kovar pedestal by glass chips. Electrodes on the microsensor and the pins of the Kovar pedestal were connected by ball soldering based on golden wires. One permanent magnet was fixed on the Kovar tube to produce a magnetic field of $\sim 1 \mathrm{~T}$ in the package. The stainless steel tube, Kovar tube and Kovar pedestal were connected by double laser welding to maintain a high strength. Moreover, gas outlets in the Kovar tube were used to form gas paths during measurements. The package prototype is shown in Figure $7 \mathrm{~b}$.

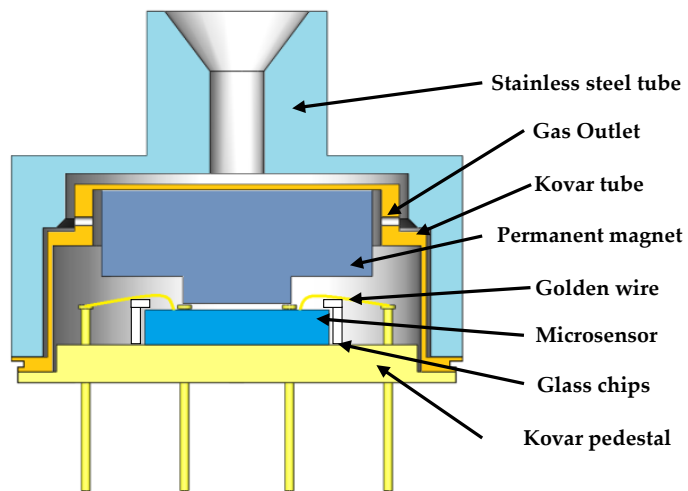

(a)

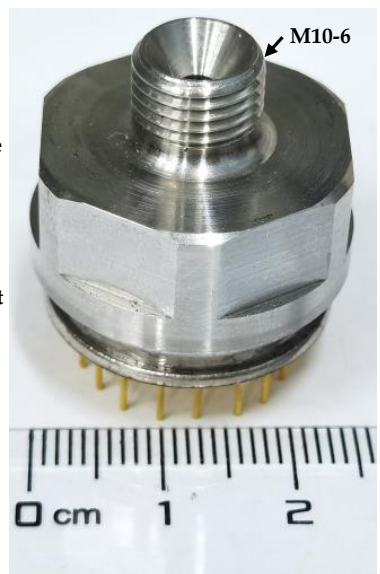

(b)

Figure 7. (a) The cross-section image of the resonant pressure sensor's packaging concept; (b) an image of the packaged microsensor. 


\section{Characterization}

The open-loop characterization was used to obtain some properties of the resonant pressure senor, such as quality factor, intrinsic frequency, signal strength and phase drift of the two resonators. First, the sensor was fixed on the open-loop circuit, which can reinforce the output signal and was connected with a network analyzer. The network analyzer was used to supply an analog signal to one side of the " $\mathrm{H}$ " beam and pick up the signal induced by the other side of the " $\mathrm{H}$ " beam.

In this way, the resonant frequency of resonator I was quantified as $91.729 \mathrm{kHz}$ with the phase drift of $\sim 160.2^{\circ}$ under a quality factor of 15,689 (see Figure 8a). Meanwhile, the resonant frequency of resonator II was quantified as $90.910 \mathrm{kHz}$ with a phase drift of $\sim 162.7^{\circ}$ under a quality factor of 15,696 (see Figure $8 b$ ).

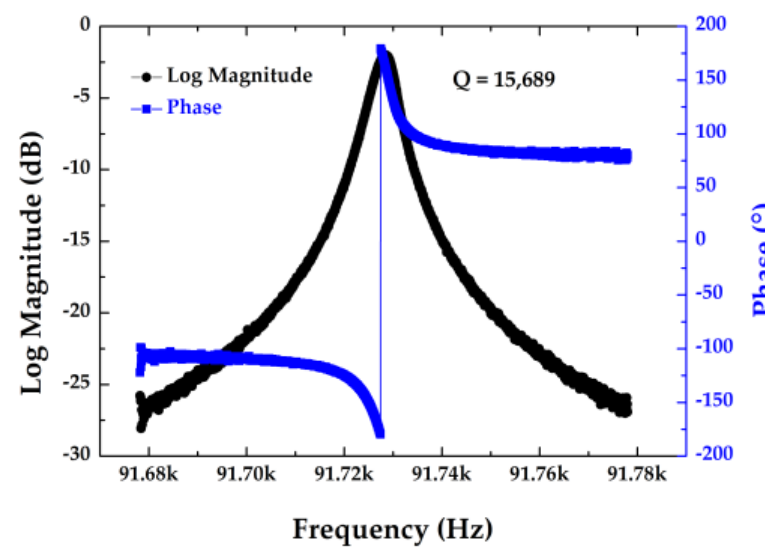

(a)

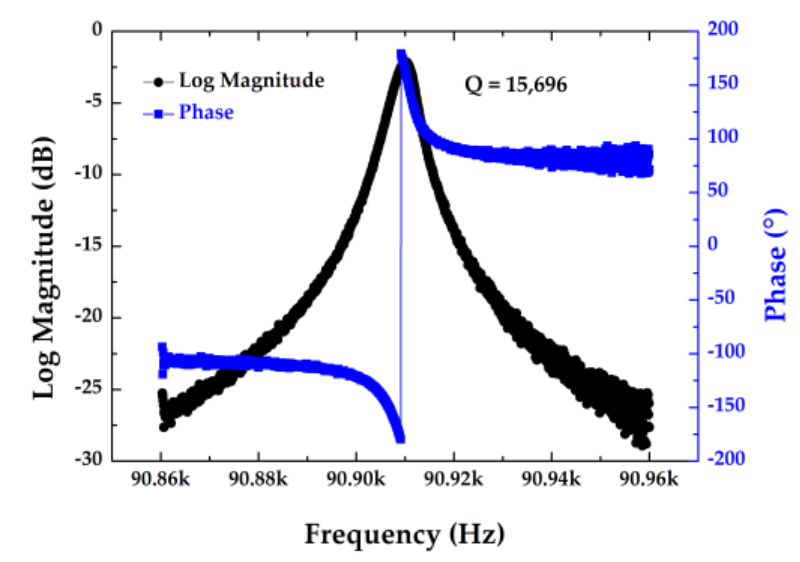

(b)

Figure 8. The properties of (a) resonator I and (b) resonator II under an atmospheric pressure of $100 \mathrm{kPa}$ and a room temperature of $25^{\circ} \mathrm{C}$.

In order to further characterize the performances of the fabricated sensor, a closed-loop circuit producing self-oscillation signals was developed. The voltage generated by the vibration of the resonator was amplified by an amplifier, and then the voltage was lowered and sent to the driving beam of the resonator for excitation in a closed loop. In order to maintain the stable vibrations of the resonator, an AGC module, including a bandpass filter, a comparator and a field effect transistor, was introduced into the closed-loop circuit.

A pressure controller (PPC4, FLUCK) and a temperature chamber (SU-241, ESPEC) were employed to provide pressure measurements and surrounding temperatures during the characterization processes. In this study, the sensor was characterized within a pressure range from $200 \mathrm{kPa}$ to $7000 \mathrm{kPa}$ and a temperature range from $-40{ }^{\circ} \mathrm{C}$ to $80^{\circ} \mathrm{C}$.

Figure 9a shows the intrinsic frequencies of two resonators as a function of pressure at $20{ }^{\circ} \mathrm{C}$, producing the sensitivities and linearly dependent coefficients of $0.51 \mathrm{~Hz} / \mathrm{kPa}$ and 0.999846 for resonator I; $-1.75 \mathrm{~Hz} / \mathrm{kPa}$ and 0.999839 for resonator II, which were consistent with the simulation results. Figure $9 \mathrm{~b}$ shows the intrinsic frequencies of the two resonators as a function of temperature. The temperature sensitivity of the differential outputs was quantified as $0.06 \mathrm{~Hz} /{ }^{\circ} \mathrm{C}$ in the temperature range from -40 to $80^{\circ} \mathrm{C}$ under an atmosphere pressure of $\sim 100 \mathrm{kPa}$. This value cannot match the result of the simulation due to the machining errors during the fabrication process. 


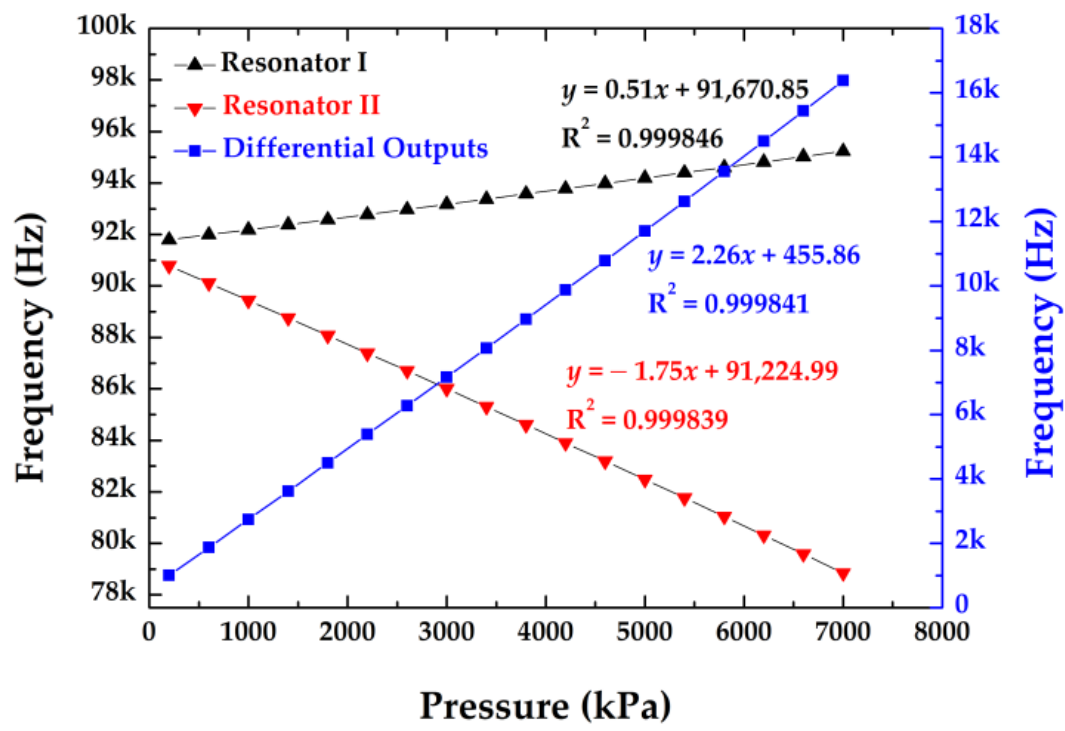

(a)

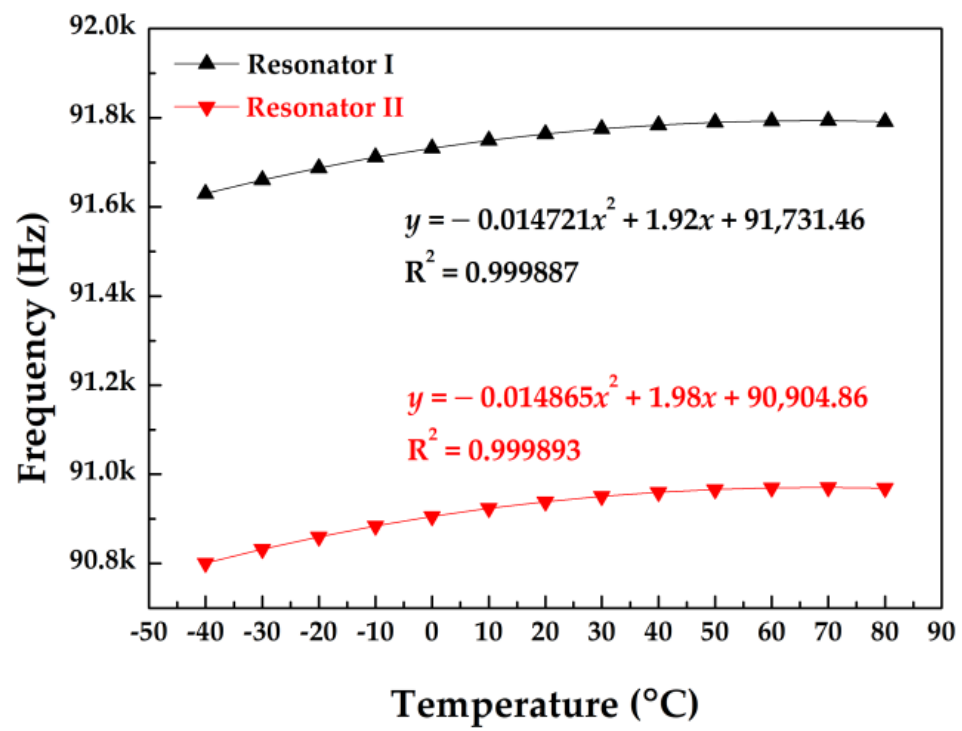

(b)

Figure 9. (a) The pressure-frequency curve of the developed sensor at $20^{\circ} \mathrm{C}$; (b) the temperaturefrequency curve of the developed sensor under atmosphere pressure of $\sim 100 \mathrm{kPa}$.

Moreover, calibrations were conducted to verify the high performance of the microsensor. Figure 10a shows the fitting errors of the fabricated sensor in the full pressure and temperature ranges with temperature compensation based on differential outputs and a temperature sensor, producing compensation errors within $\pm 400 \mathrm{~Pa}$ with corresponding $\pm 0.006 \%$ FS, which indicated that the developed sensor was stable enough under the heat conditions from $-40{ }^{\circ} \mathrm{C}$ to $80^{\circ} \mathrm{C}$. Figure $10 \mathrm{~b}$ shows the measurement errors of the sensor at the surrounding temperatures of $-40{ }^{\circ} \mathrm{C}, 20^{\circ} \mathrm{C}, 60^{\circ} \mathrm{C}$ and $80^{\circ} \mathrm{C}$ in three cycles, which demonstrated a high accuracy with quantified maximum measurement errors within $\pm 1170 \mathrm{~Pa}$ and a corresponding $\pm 0.017 \% \mathrm{FS}$. 


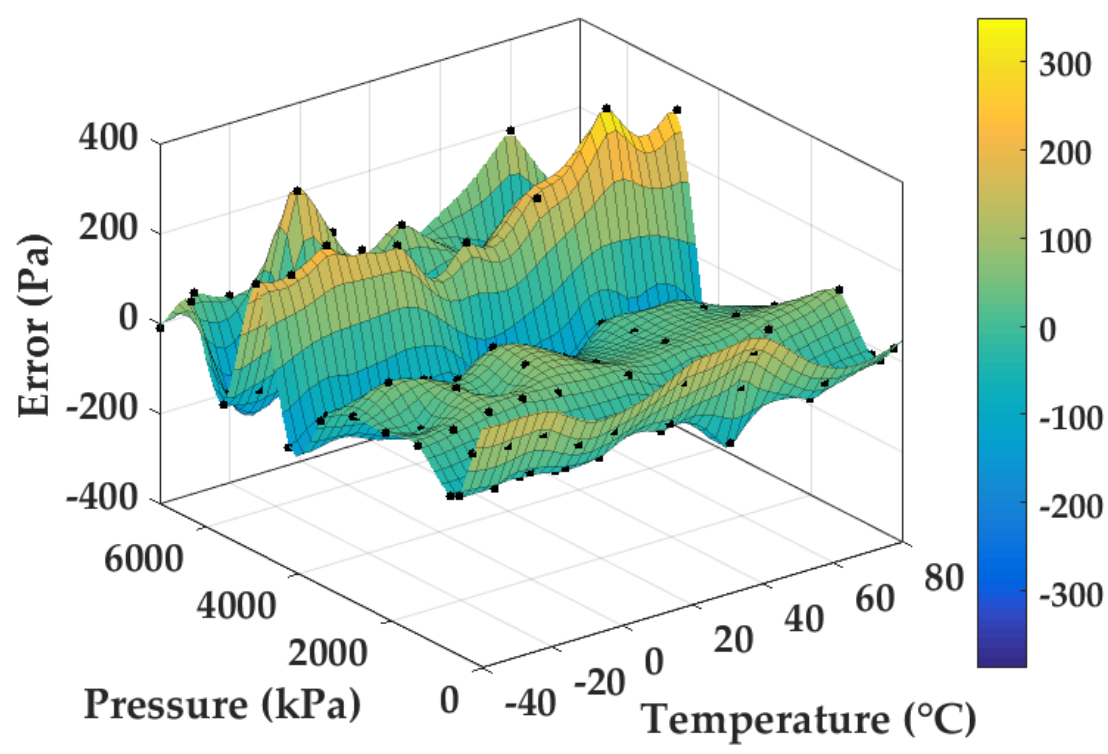

(a)

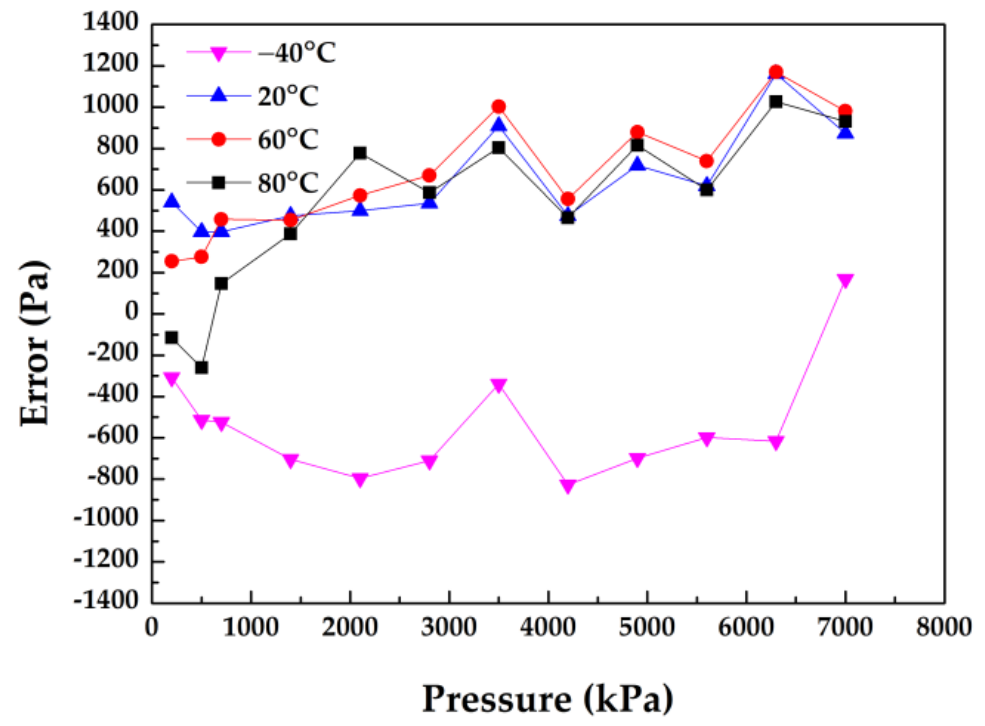

(b)

Figure 10. (a) The surface fitting of the sensor from the calibration process; (b) the measurement errors curve at $-40{ }^{\circ} \mathrm{C}, 20^{\circ} \mathrm{C}, 60^{\circ} \mathrm{C}$ and $80^{\circ} \mathrm{C}$ in three cycles.

\section{Conclusions}

A design of the resonant pressure sensor with a wide pressure measurement range was presented, where silicon islands were used to increase equivalent stiffness of the pressure-sensitive diaphragm; the SOG cap was employed to decrease the temperature sensitivity; and the cylindrical vacuum cavity was used to increase the strength of the microsensor. Meanwhile, FEA simulations were used to calculate the pressure sensitivities and temperature sensitivities. According to the simulations, the sensitivities of the two resonators were $0.56 \mathrm{~Hz} / \mathrm{kPa}$ and $-1.23 \mathrm{~Hz} / \mathrm{kPa}$, with a differential linearity of 0.999939 . The microsensor was fabricated with MEMS techniques and simple processing technologies only including two DRIE steps. The experimental results showed that the Q-factors of the 
resonator were quantified to be higher than 15,000 , which showed that the two resonant beams of the microsensor worked in a high vacuum. Besides, the pressure sensitivities of the two resonators were $0.51 \mathrm{~Hz} / \mathrm{kPa}$ and $-1.75 \mathrm{~Hz} / \mathrm{kPa}$, with a differential linearity of 0.999841. Additionally, the temperature coefficient of the differential frequency was $0.06 \mathrm{~Hz} /{ }^{\circ} \mathrm{C}$, which means that the frequency drift caused by temperature was less than $8 \mathrm{~Hz}$ from $-40{ }^{\circ} \mathrm{C}$ to $80{ }^{\circ} \mathrm{C}$. More in-depth characterizations based on the closed-loop self-oscillation system showed that the prototype demonstrated low fitting errors within $0.006 \% \mathrm{FS}$ and low measurement errors within $0.017 \%$ FS under the pressure range from $200 \mathrm{kPa}$ to $7000 \mathrm{kPa}$ in the temperature range of $-40{ }^{\circ} \mathrm{C}$ to $80{ }^{\circ} \mathrm{C}$ in three cycles.

Author Contributions: Conceptualization, J.W., D.C. and C.X.; Methodology, C.X.; Software, C.X.; Validation, C.X., C.C. and Y.L.; Formal analysis, C.X. and Y.L.; Writing-original draft preparation, C.X.; Writing-review and editing, C.X. and J.C.; Project administration, J.W. and D.C.; Funding acquisition, J.W. and D.C. All authors have read and agreed to the published version of the manuscript.

Funding: This work was supported by the National Key R\&D Program of China (2018YFB2002302 and 2018YFF01010400) and the National Science Fund for Distinguished Young Scholars (Grant No. 61825107) and the National Natural Foundation of China (Grant No. U1930206).

Conflicts of Interest: The authors declare no conflict of interest.

\section{References}

1. Ikeda, K.; Kuwayama, H.; Kobayashi, T.; Watanabe, T.; Nishikawa, T.; Yoshida, T.; Harada, K. Silicon Pressure Sensor Integrates Resonant Strain Gauge on Diaphragm. Sens. Actuators A Phys. 1990, 21, 146-150. [CrossRef]

2. Chan, E.; Lin, D.; Tang, Z.; Lu, L.; Chau, K.; Wong, M. High-pressure High-temperature Bulk-type Piezoresistive Pressure Sensor. In Proceedings of the 2018 14th IEEE International Conference on Solid-State and Integrated Circuit Technology (ICSICT), Qingdao, China, 31 October-3 November 2018.

3. Niu, Z.; Zhao, Y.; Tian, B. Design Optimization of High Pressure and High Temperature Piezoresistive Pressure Sensor for High Sensitivity. Rev. Sci. Instrum. 2014, 85, 2107-2109. [CrossRef] [PubMed]

4. Wagner, S.; Yim, C.; McEvoy, N.; Kataria, S.; Yokaribas, V.; Kuc, A.; Pindl, S.; Fritzen, C.-P.; Heine, T.; Duesberg, G.S.; et al. Highly Sensitive Electromechanical Piezoresistive Pressure Sensors Based on Large-Area Layered PtSe2 Films. Nano Lett. 2018, 18, 3738-3745. [CrossRef]

5. Chen, Z.; Wang, Z.; Li, X.; Lin, Y.; Luo, N.; Long, M. Flexible Piezoelectric-induced Pressure Sensors for Static Measurements Based on Nanowires/graphene Heterostructures. ACS Nano 2017, 11, 4507-4513. [CrossRef] [PubMed]

6. Dabrowski, A.P.; Golonka, L.J. High Pressure Sensor with PZT Transducer in LTCC Package. Procedia Eng. 2014, 87, 1099-1102. [CrossRef]

7. Rogers, T.; Kowal, J. Selection of Glass, Anodic Bonding Conditions and Material Compatibility for Silicon-glass Capacitive Sensors. Sens. Actuators A Phys. 1995, 46, 113-120. [CrossRef]

8. Tan, Q.; Li, C.; Xiong, J.; Jia, P.; Zhang, W.; Liu, J.; Xue, C.; Hong, Y.; Ren, Z.; Luo, T. A High Temperature Capacitive Pressure Sensor Based on Alumina Ceramic for in situ Measurement at $600{ }^{\circ}$ C. Sensors 2014, 14, 2417-2430. [CrossRef] [PubMed]

9. Rogers, A.J. Distributed Optical-fibre Sensors for the Measurement of Pressure, Strain and Temperature. Phys. Rep. 1988, 58, 99-143. [CrossRef]

10. Hallynck, E.; Bienstman, P. Integrated Optical Pressure Sensors in Silicon-on-insulator. IEEE Photonics J. 2012, 4, 443-450. [CrossRef]

11. Li, A.; Zhang, C.; Wang, H.; He, Y.; Sun, D.; Wang, L.; Du, X.; Gu, D. Design of Temperature-immunization System Packaging for the Resonant Pressure Sensor. Mod. Phys. Lett. B 2017, 31, 1750085. [CrossRef]

12. Welham, C.J.; Greenwood, J.; Bertioli, M.M. A High Accuracy Resonant Pressure Sensor by Fusion Bonding and Trench Etching. Sens. Actuators A Phys. 1999, 76, 298-304. [CrossRef]

13. Chen, D.; Li, Y.; Liu, M.; Wang, J. Design and Experiment of a Laterally Driven Micromachined Resonant Pressure Sensor for Barometers. Procedia Eng. 2010, 5, 1490-1493. [CrossRef]

14. Corman, T.; Enoksson, P.; Stemme, G. Low-pressure-encapsulated Resonant Structures with Integrated Electrodes for Electrostatic Excitation and Capacitive Detection. Sens. Actuators A Phys. 1998, 66, 160-166. [CrossRef]

15. Melamud, R.; Hopcroft, M.; Jha, C.; Kim, B.; Chandorkar, S.; Candler, R.; Kenny, T.W. Effects of Stress on the Temperature Coefficient of Frequency in Double Clamped Resonators. In Proceedings of the 13th International Conference on Solid-State Sensors, Actuators and Microsystems, 2005 (TRANSDUCERS '05), Seoul, Korea, 5-9 June 2005; pp. 392-395.

16. Wang, J.B.; Shi, X.J.; Liu, L.; Wu, Z.W.; Chen, D.Y.; Zhao, J. A Novel Resonant Pressure Sensor with Boron Diffused Silicon Resonator. In Proceedings of the SPIE, 2008 International Conference on Optical Instruments and Technology: MEMS/NEMS Technology and Applications, Beijing, China, 16-19 November 2008. 
17. Southworth, D.R.; Craighead, H.G.; Parpia, J.M. Pressure Dependent Resonant Frequency of Micromechanical Drumhead Resonators. Appl. Phys. Lett. 2009, 94, 213506. [CrossRef]

18. Xu, T.; Zhao, L.; Jiang, Z.; Guo, X.; Ding, J.; Xiang, W.; Zhao, Y. A High Sensitive Pressure Sensor with the Novel Bossed Diaphragm Combined with Peninsula-island Structure. Sens. Actuators A Phys. 2016, 244, 66-76. [CrossRef]

19. Li, X.; Kan, E.C. A Wireless Low-range Pressure Sensor Based on P(VDF-TrFE) Piezoelectric Resonance. Sens. Actuators A Phys. 2010, 163, 457-463. [CrossRef]

20. Pakula, L.S.; Yang, H.; Pham, H.T.M.; French, P.J.; Sarro, P.M. Fabrication of a CMOS Compatible Pressure Sensor for Harsh Environments. J. Micromech. Microeng. 2004, 14, 1478. [CrossRef]

21. Tang, D.; Yang, D.; Jiang, R.; Zhao, J.; Wang, H.; Jiang, S. Fiber Loop Ring-down Optical Fiber Grating Gas Pressure Sensor. Opt. Lasers Eng. 2010, 48, 1262-1265. [CrossRef]

22. Kim, D.H.; Lee, E.J.; Cho, M.R.; Kim, C.S.; Park, Y.D.; Kouh, T. Pressure-sensing Based on Photothermally Coupled Operation of Micromechanical Beam Resonator. Appl. Phys. Lett. 2013, 102, 59. [CrossRef]

23. Hajjaj, A.Z.; Alcheikh, N.; Hafiz, M.A.A.; Ilyas, S.; Younis, M.I. A Scalable Pressure Sensor Based on an Electrothermally and Electrostatically Operated Resonator. Appl. Phys. Lett. 2017, 111, 223503. [CrossRef]

24. Sujan, Y.; Uma, G.; Umapathy, M. Design and Modelling of a Micro Resonant Pressure Sensor. Microsyst. Technol. 2017, 23, 1285-1293. [CrossRef]

25. Tang, Z.; Fan, S.; Xing, W.; Guo, Z.; Zhang, Z. An Electrothermally Excited Dual Beams Silicon Resonant Pressure Sensor with Temperature Compensation. Microsyst. Technol. 2011, 17, 1481-1490. [CrossRef]

26. Cheng, R.; Zhao, Y.; Li, C.; Tian, B.; Yu, Z.; Liu, K. Design and Fabrication of a Resonant Pressure Sensor by Combination of DETF Quartz Resonator and Silicon Diaphragm. Microsyst. Technol. 2015, 21, 631-640. [CrossRef]

27. Greenwood, J.C. A High Pressure Resonant Sensor. In IEE Colloquium on Heading Sensors for Sonar and Marine Applications; IET: London, UK, 1994.

28. Greenwood, J.C.; Wray, T. High Accuracy Pressure Measurement with a Silicon Resonant Sensor. Sens. Actuators A Phys. 1993, 37, 82-85. [CrossRef]

29. Kinnell, P.K.; Craddock, R. Advances in Silicon Resonant Pressure Transducers. Procedia Chem. 2009, 1, 104-107. [CrossRef]

30. Jiang, Y.W.; Du, X.; Zhan, Z.; Xu, B.; Lv, W.; Wang, L. Design and Simulation of Fully-symmetrical Resonant Pressure Sensor. In Proceedings of the 7th IEEE International Conference on Nano/Micro Engineered and Molecular Systems (NEMS), Kyoto, Japan, 5-8 March 2012.

31. Mitsuya, H.; Ashizawa, H.; Sugiyama, T.; Kumemura, M. Electret-based Low Power Resonator for Robust Pressure Sensor. In Proceedings of the 27th IEEE International Conference on Micro Electro Mechanical Systems, San Francisco, CA, USA, 26-30 January 2014.

32. Lu, Y.L.; Yan, P.C.; Xiang, C.; Chen, D.Y.; Wang, J.B.; Chen, J. A Resonant Pressure Microsensor with the Measurement Range of $1 \mathrm{MPa}$ Based on Sensitivities Balanced Dual Resonators. Sensors 2019, 19, 2272. [CrossRef]

33. Yan, P.C.; Lu, Y.L.; Xiang, C.; Chen, D.Y.; Wang, J.B.; Chen, J. A Temperature-Insensitive Resonant Pressure Micro Sensor Based on Silicon-on-Glass Vacuum Packaging. Sensors 2019, 19, 3866. [CrossRef]

34. Xiang, C.; Yan, P.C.; Lu, Y.L.; Chen, D.Y.; Wang, J.B.; Chen, J. A Resonant Pressure Microsensor with Temperature Compensation Based on Differential Outputs and a Temperature Sensor. Micromachines 2020, 11, 1022. [CrossRef]

35. Bao, M.H. Analysis and Design Principles of MEMS Devices; Elsevier: Amsterdam, The Netherlands, 2005 ; pp. 97-107. 